\title{
Reporting ethics approval in health and social sciences articles. An audit of adherence to GDPR and national legislation
}

Kjell Asplund ( $\square$ kjellasplund1@gmail.com )

Department of Public Health and Clinical Medicine, Umeå University, Sweden

Kerstin Hulter Åsberg

Department of Neurosciences, Uppsala University, Sweden

\section{Research Article}

Keywords: Research ethics, ethics approval, GDPR, health sciences, social sciences

Posted Date: May 3rd, 2021

DOl: https://doi.org/10.21203/rs.3.rs-378210/v1

License: (c) (1) This work is licensed under a Creative Commons Attribution 4.0 International License.

Read Full License

Version of Record: A version of this preprint was published at BMC Medical Ethics on July 15th, 2021. See the published version at https://doi.org/10.1186/s12910-021-00664-w. 
Reporting ethical approval in health and social science articles. An audit of adherence to GDPR and national legislation.

\author{
Kjell Asplund ${ }^{1}$ and Kerstin Hulter $\AA_{\text {sberg }}^{2}$ \\ ${ }^{1}$ Department of Public Health and Clinical Medicine, Umea University, Sweden \\ ${ }^{2}$ Department of Neuroscience, Uppsala University, Sweden
}

Suggested running headline: Research ethics approval

Correspondence:

Professor Kjell Asplund

Reimersholmsgatan 59

11740 Stockholm

kjellasplund1@gmail.com

+46705732281

Conflicts of interest: None

Number of words in the main text (excluding abstract, references and illustrations):

2509

Number of illustrations:

3 tables

1 figure 


\section{Summary}

Background. Previous studies have indicated that failure to report ethical approval is common in health science articles. In social sciences, the occurrence is unknown. The Swedish Ethics Review Act applies to all human research and requests that personal data, as defined by the EU General Data Protection Regulation (GDPR), should undergo independent ethical review. We have explored the adherence to this regulation.

Methods. Using the Web of Science databases, we reviewed 600 consecutive articles from three domains (health sciences with and without somatic focus and social sciences) based on identifiable personal data published in 2020 .

Results. Information on ethical review was lacking in 12 of 200 health science articles with somatic focus (6\%), 21 of 200 health science articles with non-somatic focus (11\%), and in 54 of 200 social science articles (27\%; $\mathrm{p}<0.001$ vs. both groups of health science articles). Failure to report on ethical approval was more common in (a) observational than in interventional studies ( $<<0.01)$, (b) articles with only 1-2 authors $(\mathrm{p}<0.001)$ and (c) health science articles from universities without a medical school $(\mathrm{p}<0.001)$. There was no significant association between journal impact factor and failure to report ethical approval. Conclusions. We conclude that reporting of research ethics approval is reasonably good, but not strict, in health science articles. Failure to report ethical approval is about three times as high in social sciences. Improved adherence seems needed particularly in observational studies, in articles with few authors and in social science research.

( 242 words)

Keywords

Research ethics, ethics approval, GDPR, health sciences, social sciences 


\section{Introduction}

Failure to report on informed consent and approval by an ethics review board has been described to be frequent in clinical research, even in prestigious journals (1). Recent assessments have shown marked variations between research areas in the proportion of articles lacking information on external ethics review. The proportion has been reported to range from 6 per cent in nursing research (2) to 48 per cent in pediatric surgery (3) and 50 per cent in otolaryngology (4). Previous studies have also shown a considerable between-journal variation in the proportion of clinical articles reporting on ethical approval (1), even within one and the same discipline (5).

How research ethical review is regulated varies considerably between countries. Whereas many countries have legislation or other nationwide regulation on research ethics review, ethics review committees/institutional review boards are local or regional in most countries. Numerous studies based on multinational research projects describe widely different outcomes between countries when one and the same application is assessed; this has been called "ethics review roulette" (6). Common definitions of what are personal data, as in the European Union General Data Protection Regulation (GDPR) (7) may help to overcome some of these variations.

The Swedish system for ethical review is centralized with an Ethics Review Act that applies to all human research (8) and a national Ethics Review Authority (9). Briefly, according to the Act, ethical review is mandatory for (a) research that involves personal data according to article 9.1 in GDPR (7), (b) research that involves physical encroachment on an individual or uses a method that aims to affect the subject physically or psychologically, and (c) studies on biological material traceable to specific individuals.

There may be pros and cons of strict regulation of research ethics reviews, including lawmaking. The present study contributes with empirical information on adherence to GDPR and 
the Swedish Act as to reporting of approval by the Ethics Review Authority (or previous Regional Review Boards) in published scientific articles. We have compared failures to report this information in health and social science articles and explored in what settings failures may be particularly frequent.

\section{Methods}

To identify relevant articles, we screened Science Citation Index Expanded and Social Sciences Citation Index in the Web of Science databases (10), using "Sweden" in the address field. Consecutive articles published from January 1st 2020 onwards were screened. Articles were included if they fulfilled the following criteria: (a) health or social sciences, (b) study with original data, (c) containing personal data according to GDPR (7): racial or ethnic origin, political opinions, religious or philosophical beliefs, trade union membership, genetic data, biometric data for the purpose of uniquely identifying a natural person, data concerning health or data on sex life or sexual orientation, and (d) personal data collected in Sweden. Each article was assessed by two reviewers; discrepancies were solved by consensus discussion.

When databases from Swedish authorities are used, key codes are kept by the authorities. Therefore, data are traceable even if researchers work with a pseudonymized database, thus, GDPR and the Swedish Ethics Review Act apply.

Exclusion criteria were: (a) articles with completely anonymized individual data, (b) articles on health and social personal data not specified by GDPR (they were dominated by studies of attitudes, experiences and working conditions of healthcare and social services staff), and (c) articles based on information on deceased persons.

In each of three categories, the first 200 consecutive articles in the Web of Science databases were included: health science with somatic focus, health science with non-somatic focus and social sciences. Thus, a total of 600 articles with personal data were included. If an 
article was not available online at the university library $(\mathrm{n}=21 ; 3 \%)$, it was replaced by the next consecutive article available.

The articles were reviewed for information on approval by the Swedish Ethical Review Authority or its predecessors Regional Ethical Review Boards, including registration number. In articles without information on ethical approval but referral to a previous publication, it was reviewed. In addition, we abstracted information on publication journal, study design, research discipline, number of authors, and the corresponding author's institution. Impact factors of the journals were retrieved from Journal Citation Reports database (11).

\section{Results}

Of the 600 articles with personal data by the GDPR criteria (from 361 different journals), 87 (14.5 per cent) lacked information on approval by the Ethical Review Authority or a Regional Ethical Review Board. As shown in Figure 1 and Table 1, the proportion without information on ethical approval was modestly higher in health studies with a non-somatic focus compared to those with a somatic focus ( $11 \%$ vs. $6 \%$, statistically not significant). It was about three times higher in social science articles $(27 \%$; chi-square test $p<0.001$ vs. both groups of health science articles). Of articles reporting on ethical approval, about three quarters also reported registration number of the approval, making it traceable (Figure 1).

In health science articles with somatic focus, the proportion lacking information on ethical approval was low in all subcategories: surgical focus ( 3 of $39 ; 8 \%$ ), non-surgical focus ( 9 of $138 ; 7 \%$ ), and laboratory focus ( 0 of 13$)$. The category health science articles with nonsomatic focus was heterogenous. The proportion of articles without information on ethical approval did not differ significantly between the subgroups of mental and neurological disorders $(9$ of $84 ; 11 \%)$, nursing research $(2$ of $31 ; 6 \%)$ and the collective group of other 
disciplines $(10$ of $85 ; 12 \%)$. As shown in Table 2 , in the social science category, significant deviations from the mean $(27 \%)$ were observed for research on the elderly $(0 \%$; significantly lower) and the heterogenous group "Other" (61\%; significantly higher) which included a wide range of disciplines such as political science, economics, linguistics, sports research, communication, environmental and transportation research. Low statistical power hampered many of the comparisons of subcategories.

We classified the articles as observational and interventional studies, respectively. Observational studies included cross-sectional, case-control and cohort studies, as well as studies using qualitative methods and participant observations. Information on ethical approval was lacking about three times more often in observational compared to interventional studies (17\% vs. 5\%; p<0.01) (Table 1). Most interventional studies were in health research with a somatic focus, and the statistically significant overall difference was mainly driven by the difference in this category.

When an article had only 1 or 2 authors, lack of information on ethical approval was nearly four times as common as when there were 3 or more authors; the difference was highly statistically significant $(\mathrm{p}<0.001$; Table 1$)$.

The affiliation of the corresponding author or, in multinational studies, the author who was mainly responsible for the Swedish component of the study, was dichotomized into universities with and without a medical school (education of physicians). The great majority of studies were from universities with a medical school (475 of 600; 79\%). Overall, lack of information on ethics approval was more than twice as frequent in universities without a medical school as in those with a medical school $(\mathrm{p}<0.001$; Table 1$)$. The statistical significance was entirely driven by a marked difference among health science studies with a non-somatic focus. 
We also explored if lack of information on ethical approval was associated with a low impact factor of the journals in which the articles had been published. The mean impact factor was highest for health science articles with somatic focus and lowest for social sciences (Table 3). Within all the three major categories, the journal impact factor was similarly distributed in articles with and without information on ethical approval.

In 20 of the 87 articles lacking information on ethical approval, there was a commentary on research ethics or an explanation why approval by the Ethical Review Authority or the previous Regional Ethical Review Boards had not been obtained (Table 4). In 6 articles, the authors incorrectly stated that ethics approval was not required or not relevant. In 5 articles, the authors referred to approval by a local ethics committee at the institution or to local ethical guidelines (not compliant with the Swedish Ethics Review Act). In 7 articles without information on ethical approval, there were general reassurances that ethical guidelines had been adhered to and/or referral to the Helsinki Declaration. In 2 articles, it was correctly stated that the research was based on students' works, exempted from compulsory ethics review by law.

\section{Discussion}

Our results show that information on ethics approval of research with identifiable personal data is not reported in about one in ten articles in health sciences and in more than a quarter of articles in social sciences. The risk for non-reporting was higher in observational than in interventional studies, in articles with only one or two authors than in multi-authored articles and, as to health science articles with a non-somatic focus, in universities without a medical school compared to those with a medical school. There was no apparent association with the impact factor of the journals in which the articles were published. 
The Swedish Ethics Review Act applies not only to health sciences but also to social sciences, similarly to the regulation in some other countries, for instance Norway (12) and the United States (13). Whereas lack of information on ethical approval has been reported in a limited number of previous studies (see Introduction), we have not been able to identify any corresponding study of ethical approval in social sciences.

The proportion of articles not reporting on ethical approval has varied widely in previous mappings of health sciences articles, ranging from 3 per cent $(14)$ to 48 -50 per cent $(3,4)$. Some of the variations may be explained by the fact that many studies have been limited to a few selected journals in a specific discipline. We have included consecutive studies in the Web of Science databases, irrespective of discipline.

In the literature, there is scanty information on high-risk settings for not reporting on ethical approval. We observed that failure to report on ethical approval was much more common in articles based on observational studies than on intervention studies. This is in line with previous observations that the frequency of non-reporting is low in articles based on randomized controlled trials $(1,15)$ and lower in prospective than in retrospective studies (16).

In view of the previously reported between-journal variation in the proportion of articles not reporting on ethics review $(1,5)$, we hypothesized that failure to report on ethical approval was more frequent in articles published in low-impact than in high-impact journals. Our results did not, however, support this hypothesis. Within each of the three research domains, the impact factor distribution was similar whether or not ethical approval had been reported. There seems to be an opportunity also for editors of many high- and medium-impact journals to improve authors' reporting of ethical approval when articles are based on identifiable personal data. 
Articles with only one or two authors were associated with a high risk of not reporting on ethical approval. The chance of someone in the research group being experienced in ethics regulations would be greater in a larger team. In health science articles with a non-somatic focus, failure to report on ethical approval was much more frequent when the articles came from universities without a medical school, another indicator of the research environment being significant for adherence to ethics regulations. Medical research has a long tradition of ethical reviewing. The Ethics Review Act, that applies to all human research, has been in place since 2004 and, yet, it seems that adherence to the law is still far from strict in many social sciences. This seems to be particularly common in those social science disciplines where studies based on personal data are infrequent (in our analysis assembled in the "Others" subgroup). In the international literature, the need for ethical review of social sciences studies and its legitimacy have been questioned and the procedures for reviewing social science projects have been criticized $(17,18)$. A reason for the frequent non-reporting of ethical approval in social science may be that knowledge about the legislation is not sufficient, but it may also be an element of civil disobedience in a system with limited legitimacy among the researchers.

There are several reasons why ethical approval is not reported. Ethical approval may have been obtained but not reported in the publication. The authors may have misinterpreted the law, for instance by incorrectly assuming that it does not apply to their research. As shown by the comments in a few of the articles, the authors may wrongly think that approval by a local committee may substitute approval by the national Ethics Review Authority. The Act explicitly exempts student works, but this reason was given in only 2 of 87 articles lacking information on ethical approval. In all likelihood, the great majority of non-reporting is ascribed to lack of obtaining statutory ethical approval for research based on personal data. 
A limitation of our study is that there may be some classification bias. Many of the studies were multidisciplinary and we classified them by their main focus; there was therefore an element of subjectivity. Any possible classification bias could result in both exaggerated or reduced differences between research areas. We have restricted the delineation of personal data to the items defined in GDPR. This regulation does not cover some individual data that is usually considered to be sensitive - violent relationships, intake of illegal drugs (without overt abuse) and results of personality tests, to take a few examples. Therefore, there is a possibility that our figures on failures to report ethical approval may be somewhat underestimated. Differences between subgroups are probably not affected. In large subgroups the numbers were sufficient to make comparisons with appropriate statistical power; however, the numbers were small in many subgroups, resulting in low statistical power. It should also be noted that our investigation covers only one aspect of the ethical review process, concerning research participants' integrity. Other considerations, such as those on possible risk and benefits of the research, would have required access to full documentation of each study.

The Swedish system is centralized with an Act covering all human research and a national Ethics Review Authority. The present results show that, in this system, reporting of ethical approval is fair, although not strict, in health sciences but inadequate in social sciences. Direct comparisons with previous studies on failure to report ethical approval are complicated by differences in methodology. Nevertheless, a tentative interpretation is that the frequency of lack of information on ethics approval in health sciences (one in ten) is considerably lower than in most previous studies. In a recent update of the Swedish Ethics Review Act, a centralized inspection function was introduced (8). Our results may be helpful to identify research that is at high risk for being conducted without ethical approval: observational studies, particularly in social sciences, performed by only one or two authors and, in health sciences, executed in a university without a medical school. 


\section{References}

1. Schroter S, Plowman R, Hutchings A, et al. Reporting ethics committee approval and patient consent by study design in five general medical journals. J Med Ethics. 2006;32(12):718-23.

2. Wu Y, Howarth M, Zhou C, et al. Reporting of ethical approval and informed consent in clinical research published in leading nursing journals: a retrospective observational study. BMC Med Ethics. 2019;20(1):94.

3. Uecker M, Ure BM, Dingemann J. Ethical publication standards in articles reporting on novel surgical methods: analysis of three pediatric surgical journals. Eur J Pediat Surg. 2020;DOI: 10.1055/s-0040-1715611.

4. Murphy S, Nolan C, O'Rourke C, et al. The reporting of research ethics committee approval and informed consent in otolaryngology journals. Clin Otolaryngol. 2015;40(1):36-40.

5. Dingemann J, Dingemann C, Ure B. Failure to report ethical approval and informed consent in paediatric surgical publications. Eur J Pediatr Surg. 2011;21(4):215-9.

6. Glasziou P, Chalmers I. Ethics review roulette: what can we learn? BMJ. 2004;328(7432):121-2.

7. European Union. Regulation (EU) 2016/679 of the European Parliament and of the Council of 27 April 2016 on the protection of natural persons with regard to the processing of personal data and on the free movement of such data, and repealing Directive 95/46/EC (General Data Protection Regulation). Official Journal of the European Union. 2016;59:1-88.

8. Swedish Parliament. Lag (2003:460) om etikprövning av forskning som avser människor [Act on ethics review of human research], in Swedish. Revised 2019. https://www.riksdagen.se/sv/dokument-lagar/dokument/svensk-forfattningssamling/lag2003460-om-etikprovning-av-forskning-som_sfs-2003-460. 2003. Accessed April 25, 2021.

9. Etikprövningsmyndigheten (Swedish Ethics Review Authority). Om myndigheten [On the Authority], in Swedish. https://etikprovningsmyndigheten.se/om-myndigheten/. Accessed April 25, 2021.

10. Clarivate. Web of Science. https://clarivate.com/webofsciencegroup/solutions/web-ofscience/. Accessed April 25, 2021.

11. Anonymous. Journal Citations Reports. https://clarivate.com/webofsciencegroup/solutions/journal-citation-reports/. Accessed April 25, 2021.

12. Anonymous. Lov om organisering av forskningsetisk arbeid (forskningsetikkloven) (in Norwegian). https://lovdata.no/dokument/NL/lov/2017-04-28-23/. Accessed April 25, 2021.

13. Office for Human Research Protections. 45 CFR 46. https://www.hhs.gov/ohrp/regulations-and-policy/regulations/45-cfr-46/index.html. Accessed April 25, 2021.

14. Finlay KA, Fernandez CV. Failure to report and provide commentary on research ethics board approval and informed consent in medical journals. J Med Ethics. 2008;34(10):761-4. 
15. Pitak-Arnnop P, Sader R, Herve C, Dhanuthai K, Bertrand JC, Hemprich A. Reporting of ethical protection in recent oral and maxillofacial surgery research involving human subjects. Int J Oral Maxillofac Surg. 2009;38(7):707-12.

16. Block MI, Khitin LM, Sade RM. Ethical process in human research published in thoracic surgery journals. Ann Thorac Surg. 2006;82(1):6-11.

17. Perrault EK, Nazione SA. Informed consent - uninformed participants: Shortcomings of online social science consent forms and recommendations for improvement. J Empir Res Hum Res Ethics. 2016;11(3):274-80.

18. Gunsalus CK, Bruner EM, Burbules NC, et al. Improving the system for protecting human subjects: Counteracting IRB “Mission Creep". The Center for Advanced Study, University of Illinois. http://www.hawaii.edu/research/wpcontent/uploads/2015/06/Improving the_System_for_Protecting_Human_Subjects_CFA S_UI.pdf. Accessed April 25, 2021. 


\section{Declarations}

Ethics approval and consent to participate: The study was approved by the Swedish Ethical Review Authority (registration number 2020-05252). Consent not applicable.

Consent for publication: Not applicable.

Availability of data and material: Primary data are available at

http://www.kjellasplund.se/data-for-articles/.

Competing interests: K.A. is a member of the Swedish Ethics Review Appeals Board (a governmental organisation). K.H.Å. reports no conflict of interest.

Funding: Not applicable.

Authors contributions: K.A. designed the study, collected and analysed data, wrote the manuscript and prepared the table and the figure. K.H.A. contributed to the study design, collected and analysed data and reviewed the manuscript.

Acknowledgements: Not applicable.

Authors' information: Not applicable. 
Legend to the fígure

Figure 1. Proportion of articles reporting on ethical approval (with and without registration number) in health sciences with somatic and non-somatic focus and social sciences articles. 


\section{Figures}
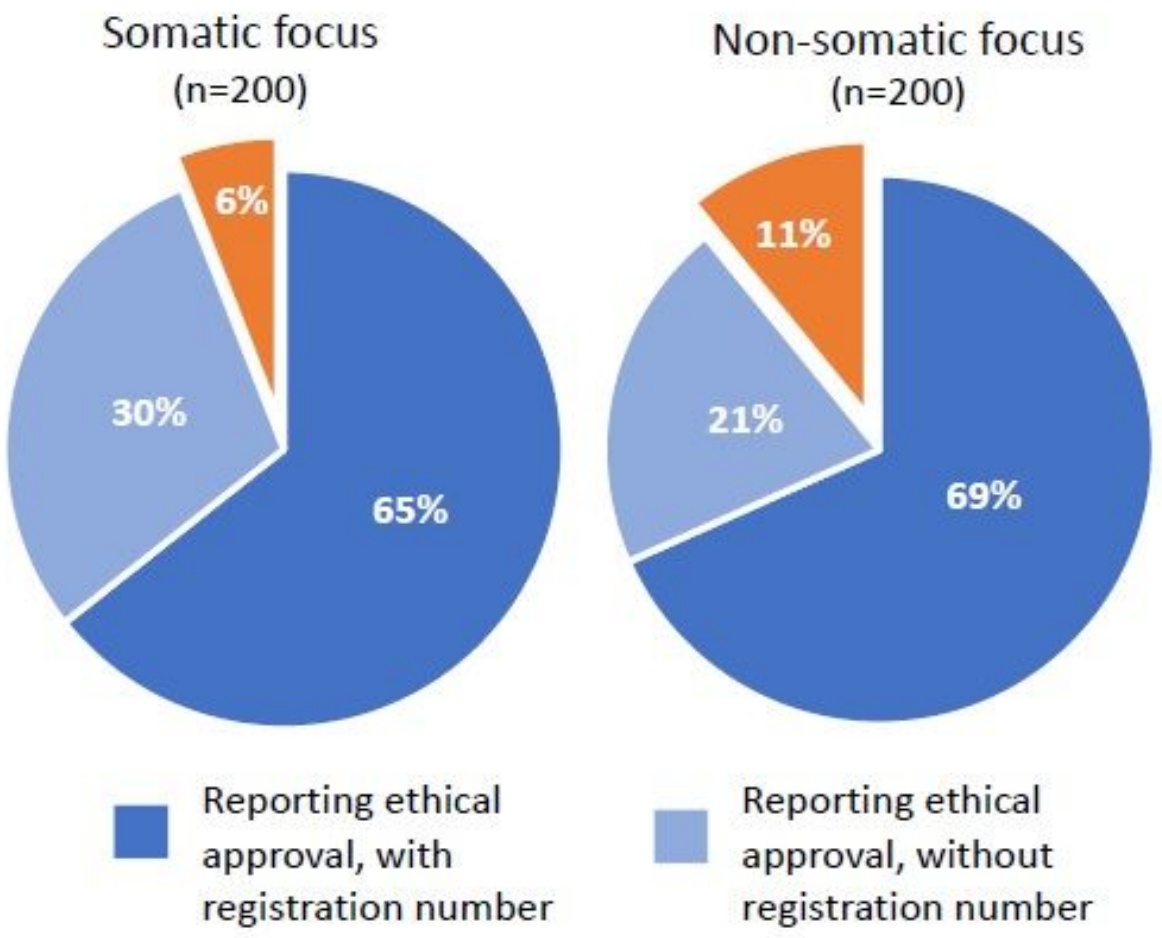

Reporting ethical approval, without registration number

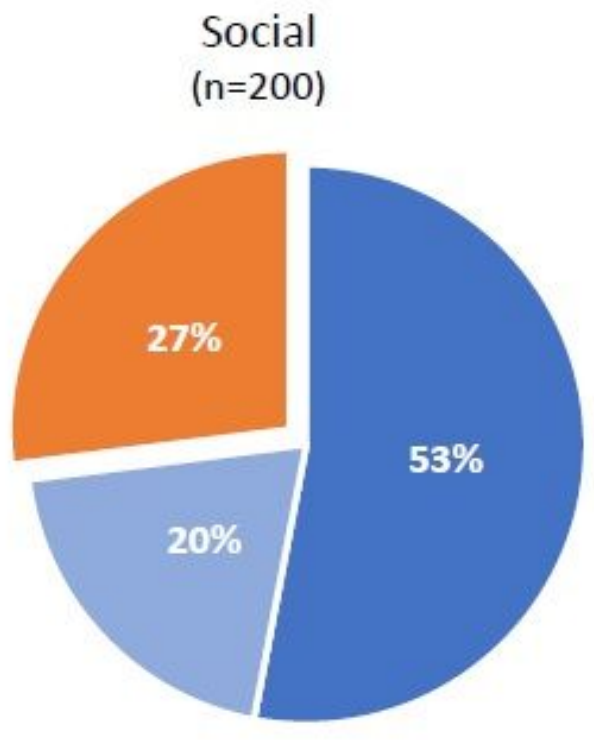

Not reporting ethical approval

\section{Figure 1}

Proportion of articles reporting on ethical approval (with and without registration number) in health sciences with somatic and non-somatic focus and social sciences articles.

\section{Supplementary Files}

This is a list of supplementary files associated with this preprint. Click to download.

- AsplundEthicsapprovalforBMCMedEthicsTablespdf.pdf 